\title{
Correction to: Assessment of ocular toxoplasmosis patients reported at a tertiary center in the northeast of Iran
}

\author{
Seyedeh Maryam Hosseini • Elham Moghaddas - Karim Sharifi • \\ Malihe Dadgar Moghaddam • Seyed Aliakbar Shamsian
}

Published online: 1 June 2018

(C) Springer Science+Business Media B.V., part of Springer Nature 2018

Correction to: Int Ophthalmol

https://doi.org/10.1007/s10792-017-0764-3

Unfortunately, in the original publication of the article, given name and family name of the first and fourth author names were mentioned incorrectly. The exact given name and family name of those author names have been provided in the erratum. The original article has been corrected.

The original article can be found online at https:// doi.org/10.1007/s10792-017-0764-3.

\section{S. M. Hosseini}

Eye Research Center, Mashhad University of Medical

Sciences, Mashhad, Iran

e-mail: HoseiniMM@mums.ac.ir

E. Moghaddas · K. Sharifi · S. A. Shamsian ( $₫)$

Department of Parasitology and Mycology, Faculty of

Medicine, Mashhad University of Medical Sciences,

Mashhad, Iran

e-mail: Shamsianaa@mums.ac.ir

M. Dadgar Moghaddam

Department of Community Medicine, Faculty of

Medicine, Mashhad University of Medical Sciences,

Mashhad, Iran 